\title{
Defining the Customer Dimension of PLM Maturity
}

\author{
Hannu Kärkkäinen ${ }^{1}$, Henk Jan Pels ${ }^{2}$, and Anneli Silventoinen ${ }^{3}$ \\ ${ }^{1}$ Department of Business Information Management and Logistics, \\ Tampere University of Technology, Finland \\ P.O. Box 541, FI-33101, Tampere, Finland \\ hannu.karkkainen@tut.fi \\ ${ }^{2}$ Department of Built Environment, \\ Eindhoven University of Technology, The Netherlands \\ P.O. Box 513, 5600MB Eindhoven, The Netherlands \\ h.j.pels@tue.nl \\ ${ }^{3}$ Department of Industrial Management, \\ Lappeenranta University of Technology, Finland \\ Skinnarilankatu 34, FI-53850 Lappeenranta, Finland \\ anneli.silventoinen@lut.fi
}

\begin{abstract}
Product lifecycle management (PLM) adoption includes very extensive changes in intra- and inter-organizational practices and requires new types of skills and capabilities. A controlled PLM implementation can therefore be very challenging in practice. PLM maturity models, often at least partly based on the thinking of CMM (Capability maturity modeling) can be used to make the implementation of PLM a better approachable and a more carefully planned and coordinated process. Our objective was to enhance current maturity modeling approaches on PLM implementation, and we have argued for and presented a novel PLM maturity dimension, "customer dimension", that we consider as an important addition to current PLM maturity models.
\end{abstract}

Keywords: PLM, customer orientation, maturity models.

\section{Introduction}

Product lifecycle management (PLM) adoption includes very extensive changes in intra- and inter-organizational practices and requires new types of skills and capabilities, and more than that, even large cultural and strategic changes. Due to the magnitude of this transformation, a controlled and proper PLM implementation can be very challenging in practice, which has been demonstrated by the difficulties companies often face in the adoption of PLM (e.g. Batenburg et al., 2006).

PLM maturity models, often at least partly based on the thinking of CMM (Capability maturity modeling) originally used in software process facilitation can be used to make the implementation of PLM better approachable and a more carefully planned and coordinated process. This is done e.g. by evaluating the current status of PLM progress, benchmarking the progress of PLM implementation between companies, helping companies to establish their own PLM strategies and goals, as well as 
helping them to choose the next steps on improving their PLM infrastructure and practices (e.g. Batenburg et al., 2006; Saaksvuori and Immonen, 2008; PLMIG, 2007; Pels and Simons, 2008).

PLM is inherently focused on the management of data, information and knowledge for creating product offerings that respond to customer needs. For instance, according to Schulte (2008), in customer-oriented PLM, the customer-related information and knowledge from all the different phases of product lifecycle should be gathered efficiently, and it should be useful and usable for streamlining the operations of all the lifecycle operations to efficiently create value for customers. However, according to Abramovici and Schulte (2007), the effectiveness and regards to current customer requirements are mostly not really a part of current PLM strategies. Thus, PLM should carefully consider customer knowledge, which can be considered from PLM perspective: (1) Knowledge 'for' customers: satisfies customers' needs for knowledge on products, the market and other relevant items (2) Knowledge 'about' customers: captures customers' background, motivation, expectation and preference on products or services (3) Knowledge 'from' customers: understands customers' usage pattern or consumption experience of products or services (Su et.al, 2007).

We noticed both from current literature and empirical studies (e.g. Kärkkäinen et al., 2012; Silventoinen et al., 2010) that the current PLM maturity models (e.g. the model of Batenburg et al., 2006) do not adequately consider the aspect of customer orientation and customer needs. Thus, we aim to introduce a novel PLM maturity dimension that we consider as an important addition to current PLM maturity models. We define the maturity of customer dimension, and we provide preliminary maturity level descriptions for this dimension. To do this, first, we base the maturity definition of customer dimension and related maturity level descriptions in the context of PLM on current literature on maturity model design and planning (e.g. Kohlegger et al., 2009). Second, we utilize a rich stream of literature to map e.g. the current developments of PLM, and studies on the future of PLM. Third, we pinpointed literature on customer-orientation in the context of PLM, as well as required customer-related competences, critical success factors related with PLM implementation.

\section{Developments and Future of PLM}

\subsection{Possibilities Provided by Information Technology}

Information technology (IT) is the driver of PLM developments. IT has three basic technologies: processing, memory and communication:

1. Processing approaches saturation since component size approaches atom size, so . pace of improvement will slow down.

2. Memory has still some 20 years to follow Moore's law. This will allow for increasing volumes of product data when moving from 3D to animated models (4D) and covering more lifecycle phases.

3. Communication has still dramatic improvements to bring. Currently glass fibre networks are being installed, able to deliver a theoretical 150Tbps. That is a leap to 10 orders of magnitude. 
As a conclusion we may state that communication power will be the driving force for the next 25 years. However, because of the infrastructural character of networks, the progress will not be gradual, but come in leaps.

\subsection{Challenges for Future of PLM Software}

The expected developments in PLM software systems will be discussed next in the 3 aspects of processing, storage and communication. Since storage is the primary function of PLM, this aspect will be considered first.

\subsubsection{Storage}

Memory is the core function of a PLM system. Not only the volume of data will double every two years, also data will become more distributed in geographical sense. The level to which a company manages to maintain access to and control over distributed product data contributes strongly to its PLM maturity.

\subsubsection{Processing}

Processing comes to the user in the form of computer applications. The challenge for PLM software vendors is to simplify the use of their complex software and at the same time provide users with flexibility within their area of expertise. Managing relationships between elements must become much easier. The most important is that engineers are seduced to use the PLM system for all their output.

From a logistic point of view the opportunity is that if the PLM system knows the process structure, the availability of resources and the real time status of all design tasks, a computer program can optimally assign tasks, eliminate waiting times, reduce lead times and make the process much more flexible.

\subsubsection{Communication}

Communication, related with collaboration, will be the driving force behind PLM development. Product lifecycle processes are increasingly distributed over different companies all over the globe. Growing complexity and increasing dependence of global service systems of products requires the involvement of an increasing number of specialists.

Social media integration in PLM has been an important trend of major PLM vendors. These emphasize the power of users to participate in the creation of content (Tredinnick, 2006). According to literature (e.g. Paroutis and Saleh, 2009; Levy, 2009), web 2.0 and social media provide quite novel ways of collaborating in the innovation process. Reflecting these developments, according to Terzi et al. (2010), all the PLM suppliers are continuously and rapidly expanding their offerings via various mergers and acquisitions of niche companies.

\subsection{Future PLM Enabling to Satisfy Customer Needs}

The benefits of PLM systems can be categorized into cost, time and quality impacts. They reduce cost by preventing expensive late changes by identifying possible 
improvements earlier in the process, e.g. integrating customer knowledge to PLM. Throughput time is reduced by finer control of processes, the benefit of which is to enable customers to refine requirements, and engineers to make optimal design decisions shorter before start of use of the product. Quality is improved by reuse of proven and reliable product knowledge and data, by supporting detailed and validated product definitions at more generic levels like product family, building block and proven technologies.

All together a total improvement of 3 orders of magnitude in product definition output may be set as PLM ambition: make product development a repetitive process to satisfy unique customer needs.

\section{Current PLM Maturity Models}

In general, "maturity" can be defined as "the state of being complete, perfect or ready" (Simpson and Weiner 1989). Maturity thus implies an evolutionary progress in the demonstration of a specific ability or in the accomplishment of a target from an initial to a desired or normally occurring end stage (Mettler, 2011). Maturity aims at systematically increasing the capabilities of a business process and the organization to deliver higher performance over time (van Looy et al., 2010). Some major indicators of the organization's improved maturity are related to predictability, control and effectiveness (Paulk et al., 2006). First, as maturity increases, the differences between targeted and actual results decreases across projects, which indicates an improved predictability. Second, the variability of actual results around targeted results decreases along the maturity increase, indicating increased control. Third, in overall, the targeted results improve as the maturity of the organization increases, indicating improved effectiveness. Thus, the overall maturity indicators and individual maturity dimensions of PLM should reflect the above three indicators in the context of PLM maturity.

According to Mettler (2011), basic elements of all maturity models are number of dimensions (such as the 'process areas' in CMM), number of levels (typically three to six), a descriptor for each level (such as the CMM's differentiation between initial, repeatable, defined, managed, and optimizing processes), a generic description or summary of the characteristics of each level as a whole, a number of elements or activities for each dimension, and a description of each element or activity as it might be performed at each level of maturity. In this study, we concentrate on the four uppermost characteristics.

Since the key effect of PLM is to enable better response to customer needs, we define PLM maturity as: The ability to manage the knowledge and capabilities of an organization to respond effectively to specific customer needs, at any point in time. This ability requires in the first place that customer needs and company capabilities are identified, that a roadmap for future development of both is maintained and that a strategy is developed to keep customer needs and company capabilities well balanced. Capabilities are based on knowledge, so knowledge must be managed. Therefore all relevant knowledge elements must be identified, related and specified. Because knowledge is constantly evolving, and the ability of the company to respond to customer needs depends on the speed with which new knowledge is developed 
and put in place in the proper processes, the process in which knowledge is created and delivered must be specified and controlled. Flexibility depends largely on the people that execute the processes. Therefore people must be motivated to perform their tasks in a flexible way with focus on the customer needs. Finally, since the changes are driven by IT development, the IT means must be in place to support and enable all processes and a proper plan for the pace in which to follow new IT developments must be in place.

In the literature there can be found several maturity modelling approaches that are directly or at least quite closely related to the important aspects of PLM implementation. These include the PLMIG model, CMM/CMMI, RACE, and the most widely academically studied Batenburg model (see Pels and Simons, 2008; PLMIG, 2007; Silventoinen et al., 2010). Generally, the concept of PLM maturity assessment is based on the CMM/CMMI where maturity is supposed to develop through a set of maturity levels, which can be measured along a set of maturity dimensions.

The existing maturity models varied in many respects. Of all the currently available models, only the generic PLM model of Batenburg et al. (2006) is represented in the academic literature, as well as well grounded in theory and empirical evidence. The assessment framework developed by Batenburg et al. (2006) was thus selected to form the basic analytical framework for this paper.

The Batenburg maturity model applies four maturity levels: Ad hoc, Departmental, Organizational and Inter-organizational on five managerial dimensions: Strategy\&Policy, Monitoring\&Control, Organisation\&Processes, People\&Culture and Information Technology. In the current PLM related models, the choice of levels and dimensions can be quite different and depends very much on the underlying vision on how the subject area evolves.

According to earlier empirical studies (Kärkkäinen et al., 2012; Silventoinen et al., 2010), the studied companies implied strongly that since PLM implementation affects closely also the customers' operation and brings changes to customers' processes, and thus the advancement in the PLM maturity stages should take better into consideration the current stage and the development of the customers' PLM maturity, as well. This indicates a strong motivation to evaluate and enhance the customer-orientation in both the generic PLM context and in the context of PLM maturity modeling.

In this paper we will now focus on one aspect of the maturity modeling which is currently not well-represented in PLM maturity models: the customer orientation and customer dimension of PLM maturity.

\section{Customer-Orientation in PLM}

PLM is inherently focused on the management of data, information and knowledge for creating product offerings that respond to customer needs. Thus, PLM should strongly consider customer and market needs and take the customer sufficiently into consideration in the product lifecycle activities. According to Schulte (2008), in customer-oriented PLM, the customer information from all the different phases of product lifecycle should be gathered efficiently, and the information should be useful and usable for streamlining 
the operations of all the lifecycle operations to efficiently create value to customers. In this section, we describe various issues and challenges of customer -orientation in PLM, as well as various customer -related competences needed in PLM to enable us to define what customer maturity means specifically in PLM context.

\subsection{Issues in the Customer Orientation of PLM}

Some major generic challenges in the customer-orientation of PLM are that customerrelated information and knowledge is easily scattered along the different phases of product's lifecycle, as well as in different persons, functions, companies and other stakeholders that participate in the different lifecycle phases of a product. In addition, much customer information is scattered in different information systems. All this, along with the huge amount of customer information makes the management of customer information along the product lifecycle an extremely challenging task.

The beginning of life (BOL) customer information related to product design and production should be used to streamline operations of middle of life (MOL) as well as the end of life (EOL). Furthermore, MOL and EOL information should also go back to designers and production engineers for the improvement of BOL decisions (Kiritsis et. al, 2008). However, according to Abramovichi and Schulte (2007), the effectiveness and regards to current customer requirements are mostly not really a part of current PLM strategies.

As the number of actors and interactions between processes regarding product information increases, new requirements are placed to the successful implementation process of PLM. In addition to technical systems implementation, the organizational and inter-organizational processes which handle for example customer information have to change also (Garetti et al., 2005).

When the main effect of PLM is to bring better response to customer needs, knowing and understanding these needs must be a key element of PLM maturity. Immediate response to actual customer needs is only possible, if the capabilities of the company are in line with these customer needs. Because of the development towards extended enterprises and extended products, not only the capabilities of a company strongly depend on the capabilities of its supply network partners, but also the needs of the customer are strongly influenced by the developments in other products in the services system in which the customer operates. In the ideal situation a mature company must have a well maintained model, covering past and future, of the customer needs, the customers service system, the own capabilities and the supply chain capabilities. There must be a strategy in place to develop capabilities in line with expected needs.

Unlike PDM systems which focus on managing data, PLM, at its core, is a process which supports capture, organization and reuse of knowledge throughout the product lifecycle (Ameri and Dutta, 2005). This requires new skills and competences. They define in their study the lifecycle knowledge as "the knowledge generated or consumed by various processes throughout the product's lifecycle". Therefore, PLM knowledgebase is (ibid) not necessarily a physically centralized repository of knowledge, but an interconnected network of disperse actors (e.g. customers, partners and 
suppliers) and knowledge repositories which are virtually unified using IT solutions. The related PLM knowledge management competence could thus be defined as the capability to integrate different processes and their corresponding agents during the product's lifecycle from the perspective of creating, utilizing and distributing knowledge. More precisely, PLM knowledge is partly explicit knowledge, recorded in documents. The rest is tacit knowledge, as present in people. Current PDM techniques are suitable for managing explicit knowledge. If however tacit knowledge is to be managed, it must at least be identified and defined in some description. Also it must be linked to the actors (persons, departments, companies) who have this knowledge.

\subsection{Customer-Related Capabilities in PLM}

We describe here major PLM capabilities needed for PLM implementation that are most relevant from the customer perspective, identified in literature. These should be reflected in PLM maturity dimensions and PLM maturity, and the customer dimensions in particular.

Concerning the generic challenges of extended enterprises and extended products, which are raised in the course of PLM implementation, the number of actors and interactions between processes regarding the successful handling of product information increases. Thus, new requirements are placed to the successful implementation of PLM. In addition to technical systems implementation, the organizational and interorganizational processes which handle for example customer information have to change also (Garetti et al., 2005). Extending the customer-orientation of PLM is certainly not solely a technical issue, but requires changes also in the customer-related capabilities of the actors participating in the PLM processes.

According to Campbell (2003), in the general sense the term "customer knowledge competence" refers to the processes that generate and integrate information about customers. Campbell (2003) defines customer knowledge competence being composed of four main organizational processes, together generating and integrating customer knowledge within the organization. These include (1) a customer information process; (2) marketing-IT (information technology) interface; (3) senior management involvement; and (4) employee evaluation and reward systems. Customer information process is an organizational process that generates customer knowledge, while the other three components can be seen as organizational processes that integrate customer knowledge throughout the organization. Generally clearly more attention is spent on processes to generate customer knowledge than to ones that integrate the knowledge throughout the company (ibid).

Also more specific competences and capabilities have been identified recently in relation to for example customer relationship management (CRM). Elements common to all CRM definitions refer, according to Campbell (2003), to leveraging technologies to engage individual customers in meaningful dialogue in order for companies to customize their products to attract, develop and retain their customers. The capability perspective on CRM highlights the fact that firms must invest in developing and acquiring a complex mix of resources that enables them to modify their behavior towards individual customers or groups of customers on a continual basis. Some major capabilities needed are related to the topics of knowledge management and interaction management (Zablah et al., 2004). 
To succeed, it is not sufficient to focus only on one set of capabilities. For instance, customer- related capabilities have to be balanced with technological ones: an important issue discovered in literature is that the complementarity of both technological and customer or marketing capabilities is the most important determinant of superior financial performance e.g. in studied high-tech markets (Duta et al., 1999; Song et al., 2005).

\section{Defining Customer Dimension of Maturity in PLM Context}

Considering the above-described definitions of PLM, PLM maturity, and the contents of the previous sections, we have arrived at defining maturity of customer dimension in the specific context of PLM as

"Capability for management of all customer- related data, information and knowledge concerning the whole lifecycle of products in such a way that it enables a company to identify and respond to individual customers' needs in a proactive way."

According to Fraser et al. (2002), existing maturity models share the common property of defining a number of dimensions at several stages of maturity, with a defined description of typical performance at the different levels of granularity. A maturity level represents a new level of organizational capability achieved by the transformation of one or more domains of an organization's processes. There are various ways to define maturity levels in current literature. In the preliminary level descriptions of maturity in customer dimension we discern the following main levels: Chaotic, Conscientious, Managed, Advanced and Integration stages.

On the basis of the earlier literature and the earlier maturity models related to PLM, we distinguish some major themes that are essential in the below maturity descriptions: level of proactivity, extent of coordination, extent of integration, and quality and type of customer knowledge. Level of proactivity means the company's capability of understanding the future in the sense of customer dimension. Extent of coordination means the extensiveness of intra- and inter-organizational systems in the customer respect. Extent of integration means the level of integration that the company can do between customer knowledge and related organizational processes and ICT tools as well as between different product lifecycle phases. Quality and type of customer knowledge refers to the variety and richness of customer knowledge (explicit/tacit, structured/unstructured, etc.) that the company is able to gather and transfer to all necessary persons.

Table 1. Descriptions of maturity stages of the PLM customer dimension

Maturity stages Description of typical performance

Level I Chaotic stage

Level of coordination is low - customer knowledge is fragmented in isolated IT tools and in product lifecycle phases, and stays mostly in people's heads. Quality of customer knowledge: information cannot be explicated and easily transferred to other people. Customer knowledge is used in reactive way for strategy and product processes. 
Level II. Conscientious stage

Level III. Managed stage

Level IV. Advanced stage
Customer knowledge management (CKM) is random, no connection with PLM exists. Organization has no formal processes, structures and tools for gathering, sharing and using customer information and knowledge for business strategy, product portfolio management and product development. Individuals may have ample knowledge but do not know how to harness it in a structured manner in order to derive business benefits. Information technology does not support systematic communication and collaboration in relation with customer information and knowledge.

Level of coordination is mainly at functional level. Part of customer knowledge can be explicated and transferred / understood in the same manner mainly at functional level. Organization recognizes the necessity of making scattered customer knowledge in isolated IT tools, product lifecycle phases and heads of individuals as part of strategy and product processes.

A practical definition of CKM within organization is explored and consideration of its applicability for PLM is made. Strategy, customer and product processes are partly considering also customer knowledge management tasks, but transferability of customer knowledge is weak. Organization recognizes the need to have formal processes, structures and tools for gathering, sharing and using customer information and knowledge for business strategy, product portfolio management and product development. Processes and communication are supported by isolated IT tools.

Level of coordination is reaching cross-functional and company level. Customer knowledge is partially integrated to processes, structures and IT tools for business strategy, product portfolio management and product development. Quality of customer knowledge is satisfactory.

Systematic CKM - formal processes, structures and tools has been described and established within an organization for gathering, sharing and using customer information and knowledge for business strategy, product portfolio management and product development. Customer knowledge is partly integrated with PLM. There is some evidence of the business value of capturing lessons learned, transferring and using customer knowledge. Some IT tools for organizationwide communication and collaboration are in use.

Level of coordination is dyadic in inter-organizational relationships. Organization is capable to use systematic CKM, thus fully integrating customer, strategy and product processes with PLM throughout product lifecycle phases, thus capable to use customer knowledge proactively in short term. Co-creation is carried out with individual partners to create and transfer new customer knowledge.

Managers are able to harness customer knowledge from all the touch points in the organization and realize the business benefits from it. The systematic process management, 
Level V. Integration stage measures of performance are used to plan and track processes. Advanced IT tools are used for communication and collaboration within organization and with individual stakeholders mainly at dyadic level.

Level of coordination is extensive, reaching interorganizational networks. Organization has customer-centric and future-oriented business culture, based on continuous improvement, flexibility and self optimization as well as well-defined, information-rich communication and cooperation networks with customers and other important actors (e.g. suppliers, partners). Co-creation and co-experimenting between customers and partners is widely adopted to create new customer knowledge and enable it to be transferred effectively within the collaborative inter-organizational and intra-organizational networks.

Thus the organization has clear vision about future customer needs, and it possesses and systematically develops the capabilities to adapt flexibly and in a proactive manner to meet new customer needs and requirements in changing business environment. These capabilities are presented in the integration and fusion of internal, external, existing, and up-to-date customer knowledge and information regarding product, service, operational processes and management discipline throughout all product lifecycle phases and value networks. Quality of customer knowledge is at high level.

\section{Discussion and Conclusions}

Our objective was to enhance current maturity modeling approaches on PLM implementation. We have argued for and presented a novel PLM maturity dimension that we consider as an important addition to current PLM maturity models. We have defined the maturity of "customer dimension" in the specific context of PLM, and provided preliminary maturity level descriptions for this dimension.

The study demonstrates that even though the topic of maturity modeling has been shown to be a useful approach in facilitating PLM implementation in many ways, we are still partly in preliminary stages in defining PLM maturity. Current models do not address the issue of customer-orientation in a very in-depth manner, and do not provide very useful guidelines on improving the customer-orientation in PLM context. They should also provide more concrete ways to separate less advanced from more advanced companies in this important PLM maturity issue. PLM maturity should focus on the concept of managing "customer knowledge", instead of overly concentrating on managing customer data and information, which have traditionally been the foci of various PLM and CRM information systems.

Our suggestion for defining maturity of customer dimension in the context of PLM suggests for instance that in order to advance to the higher levels of maturity, the traditional PLM and CRM information systems should be complemented with several features and possibilities of more recent advancements in IT. Future PLM software should enable the companies to capture and share better not only customer data and 
information, but need to capture, enhance and deploy also unstructured, tacit and future-oriented customer knowledge. The features include 3D product models, 4D simulation of both product concepts and processes, and various web2.0-based approaches. A major challenge is that these should be learned to be used synergistically, such as combining visual 3D models, simulation and intra-organizational and customer/partner communities to better deploy and experiments with new ideas, as well as get useful feedback from them.

In the future research we will elaborate the maturity level descriptions of customer dimension, and identify more detailed elements and activities for each maturity level. In addition the future research will be addressed to develop a PLM maturity assessment tool that considers customer dimension and provides guidelines to develop PLM maturity in balanced way.

\section{References}

Abramovichi, M., Schulte, S.: Product lifecycle management. In: Krause, F.-L., Franke, H.-J., Gausemeier, J. (eds.) Innovationspotenziale in der Productentwicklung, Hanser, München (2007); Quoted in Schulte (2008)

Ameri, F., Dutta, D.: Product Lifecycle Management: Closing the Knowledge Loops. Computer-Aided Design and Applications 2(5), 577-590 (2005)

Campbell, A.J.: Creating customer knowledge competence: managing customer relationship management programs strategically. Industrial Marketing Management 32(5), 375-383 (2003)

Duta, S., Narasimhan, O., Rajiv, S.: Success in high-technology rnarkets: Is marketing capability critical? Marketing Science 18(4), 547-568 (1999)

Fraser, P., Farrukh, C., Gregory, M.: Managing product development collaborations - a process maturity approach. Journal of Engineering Manufacture 217(11), 1499-1519 (2003)

Garetti, M., Terzi, S., Bertacci, N., Brianza, M.: Organisational change and knowledge management in PLM implementation. Int. J. Product Lifecycle Management 1(1), 43-51 (2005)

Kärkkäinen, H., Myllärniemi, J., Okkonen, J., Silventoinen, A.: Maturity Assessment for Implementing and Using Product Lifecycle Management in Project-oriented Engineering Companies. Int. J. Electronic Business (forthcoming in 2012)

Kiritsis, D., Nguyen, V.K., Stark, J.: How closed-loop PLM improves Knowledge Management over the complete product lifecycle and enables the factory of the future. Int. J. Product Lifecycle Management 3(1), 54-77 (2008)

Kohlegger, M., Maier, R., Thalmann, S.: Understanding Maturity Models Results of a Structured Content Analysis. In: Proceedings of I-KNOW 2009 and I-SEMANTICS 2009, Graz, Austria, September 2-4 (2009)

Mettler, T.: Maturity assessment models: a design science research approach. Int. J. Society Systems Science 3(1/2), 81-98 (2011)

Paroutis, S., Saleh, A.: Determinants of knowledge sharing using Web 2.0 technologies. Journal of Knowledge Management 13(4), 52-63 (2009)

Paulk, M., Weber, C., Curtis, B., Chrissis, M.: The capability maturity model - Guidelines for improving the software process. Addison-Wesley, Indianapolis (2006)

Pels, H.J., Simons, K.: PLM Maturity Assessment. In: ICE 2008 The 14th International Conference on Concurrent Enterprising: Concurrent Innovation: a New Wave of Innovation in Collabarative Networks, Lisbon, Portugal, June 23-25, pp. 645-652 (2008) 
PLMIG, PLM Maturity Reference Manual (Version 1.0), PLM Interest Group, 50 pages (March 19, 2007)

Saaksvuori, A., Immonen, A.: Product Lifecycle Management. Springer, Berlin (2008)

Schulte, S.: Customer centric PLM: integrating customers' feedback into product data and lifecycle processes. Int. J. Product Lifecycle Management 3(4), 295-307 (2008)

Silventoinen, A., Pels, H.J., Kärkkäinen, H., Lampela, H., Okkonen, J.: PLM Maturity Assessment as a Tool for PLM Implementation Process. In: PLM 2010 Conference, Bremen, Germany (2010)

Simpson, J.A., Weiner, E.S.C.: The Oxford English Dictionary. Oxford University Press, Oxford (1989)

Song, M., Droge, C., Hanvanich, S., Calantone, R.: Marketing and technological resource complementarity: An analysis of their interaction effect in two environmental contexts. Strategic Management Journal 26, 259-276 (2005)

$\mathrm{Su}$, C.-T., Chen, Y.-H., Sha, D.Y.-J.: Managing product and customer knowledge in innovative new product development. Int. J. Technology Management 39(1/2), 105-130 (2007)

Terzi, S., Bouras, A., Dutta, D., Garetti, M., Kiritsis, D.: Product Lifecycle Management, from its history to its new role. International Journal of Product Lifecycle Management 4(4), 360-389 (2010)

Tredinnick, L.: Web 2.0 and business. Business Information Review 23(4), 228 (2006)

van Looy, A., De Backer, M., Poels, G.: Which maturity is being measured? A classification of business process maturity models. In: 5th SIKS/BENAI Conference on Enterprise Information Systems, Eindhoven, pp. 7-16 (2010)

Zablah, A.R., Bellenger, D.N., Johnston, W.J.: An evaluation of divergent perspectives on customer relationship management: Towards a common understanding of an emerging phenomenon. Industrial Marketing Management 33(6), 475-489 (2004) 